\title{
Microsatellite Markers for Raspberry and Blackberry
}

\author{
Nina R.F. Castillo and Barbara M. Reed \\ USDA-ARS, National Clonal Germplasm Repository, 33447 Peoria Road, Corvallis, OR 97333-2521
}

Julie Graham

Scottish Crop Research Institute, Invergowrie, Dundee DD2 5DA, U.K.

Felicidad Fernández-Fernández

East Malling Research, New Road, East Malling, Kent ME19 6BJ, U.K.

Nahla Victor Bassil ${ }^{1}$

USDA-ARS, National Clonal Germplasm Repository, 33447 Peoria Road, Corvallis, OR 97333

\begin{abstract}
AdDitional INDEX worDs. Rubus idaeus, hybrids, simple sequence repeats
AbStract. Twelve microsatellites were isolated from simple sequence repeat (SSR)-enriched genomic libraries of 'Meeker' red raspberry (Rubus idaeus) and 'Marion' blackberry (Rubus hybrid). These primer pairs plus one developed from a GenBank red raspberry sequence were evaluated in 48 raspberry and 48 blackberry genotypes. Only RhM031 did not generate a product in raspberry, whereas RiG001 failed to amplify in blackberry and hybrid accessions. The number of polymerase chain reaction products per primer pair in the 12 SSRs that successfully amplified was higher in blackberry genotypes and their hybrids than in raspberry, ranging from three to 29 in blackberry (average, 14.4) and from one to 15 in red raspberry (average, 7.5). Diversity estimates were determined for 10 of 12 SSRs that amplified up to two products in 44 red raspberry genotypes. The best SSR loci based on high observed and expected heterozygosities, high polymorphism information content, and low inbreeding coefficient were RiM019, RhM003, and RhM011. They mapped to three different linkage groups $(5,2$, and 7 , respectively) in red raspberry and differentiated the unique genotypes identified with the 12 SSRs in each crop type.
\end{abstract}

Most of the cultivated fruit species in Rubus belong to two subgenera: Idaeobatus (raspberry) and Rubus (formerly Eubatus) (blackberry). Idaeobatus contains european red raspberry ( $R$. idaeus), north american red raspberry ( $R$. strigosus), black raspberry ( $R$. occidentalis), and purple raspberry $(R$. $\times$ neglectus). In Pacific Northwestern North America, raspberry and blackberry are important fruit crops where they are sold as fresh fruit and in a number of processed items like juice, yogurt, and desserts. The gross value of caneberries tops $\$ 45$ million annually in Oregon [U.S. Department of Agriculture (USDA), 2006].

The USDA-Agricultural Research Service National Clonal Germplasm Repository (NCGR) in Corvallis maintains greater than 2000 Rubus accessions, including $\approx 190$ species from 64 countries. This collection is an asset to breeders and researchers interested in conserving genotypes and increasing genetic diversity in cultivated raspberry and blackberry. Efficient germplasm management requires tools for identity verification, species characterization, and genetic diversity assessment.

Because the accurate characterization of Rubus germplasm using morphological markers is difficult, molecular markers provide more reliable means for cultivar identification and to

Received for publication 9 Mar. 2010. Accepted for publication 14 Apr. 2010. This work was supported by USDA-ARS CRIS 5358-12000-038-00D. Nina Castillo was supported by a Fulbright fellowship. Mapping in the $\mathrm{AB} \times \mathrm{MJ}$ raspberry progeny was funded by the Worshipful Company of Fruiterers (London, U.K.).

We thank Barb Gilmore for her dedication and technical assistance and Kim Hummer for manuscript review. We also thank Michael Dossett for repeating the genotyping on some accessions that had ambiguous results.

${ }^{1}$ Corresponding author. E-mail: nahla.bassil@ars.usda.gov. assess genetic relatedness and diversity in these collections. Microsatellite markers were only recently developed from an expressed sequence tag library of 'Merton Thornless' (Lewers et al., 2008). A limited number of simple sequence repeats (SSRs) are reported for Rubus, which include the invasive weed R. alceifolius (Amsellem et al., 2001), an Azorean island endemic species $R$. hochstetterorum (Lopes et al., 2006), and red raspberry (Graham et al., 2002, 2004, 2006; Woodhead et al., 2008). In this study, we developed four microsatellite markers from a genomic library of 'Meeker' raspberry, eight from a library of 'Marion' blackberry, and one from a R. idaeus GenBank sequence. These 13 SSRs were evaluated in 48 accessions of red raspberry and 48 cultivars of blackberry and mapped in two red raspberry mapping populations.

\section{Materials and Methods}

Microsatellite marker development. Two DNA libraries were constructed for SSR development: 'Meeker' raspberry and 'Marion' blackberry. A phenol:chloroform step was added to the modified PUREGENE DNA extraction protocol routinely used at the NCGR (Bassil et al., 2008). Microsatellite enrichment followed the protocol of Glenn and Schable (2005). Sequences from the genomic library were screened for the presence of microsatellites with SSRIT software (Temnykh et al., 2001) and aligned using CAP 3 software (Huang and Madan, 1999). Primer 3 software (Rozen and Skaletsky, 2000) was used for primer design. Four primer pairs from the 'Meeker' library (prefix RiM for $R$. idaeus 'Meeker'), eight primer pairs from the 'Marion' library (prefix RhM for Rubus hybrid 'Marion'), and one pair developed from a $R$. idaeus 
Genbank sequence (prefix RiG for R. idaeus GenBank) (Table 1) generated polymorphic DNA fragments of the expected size in 12 raspberry and blackberry test sets (Table 2). These 13 primer pairs were further used to fingerprint 48 raspberry and 48 blackberry accessions (Table 2).

SimPle SEQUENCE REPEAT GENOTYPING. DNA was extracted from young expanding leaves in the spring using a modified PUREGENE protocol routinely used at the NCGR (Bassil et al., 2008). The optimum annealing temperature for each primer pair was determined by gradient polymerase chain reaction (PCR) from 55 to $65^{\circ} \mathrm{C}$ using an equimolar mix of the DNA templates used for library construction. Success of the PCR was determined by $3 \%$ agarose gel electrophoresis. For genotyping, PCR was performed separately for each primer pair using a fluorescently labeled forward primer and an unlabeled reverse primer. Reactions were performed in $15-\mu \mathrm{L}$ volumes containing $1 \times$ reaction buffer, $2 \mathrm{~mm} \mathrm{MgCl}_{2}, 0.2 \mathrm{~mm}$ dNTPs, $0.15 \mu \mathrm{M}$ of each primer, $0.025 \mathrm{U}$ of Biolase Taq DNA polymerase (Bioline USA, Taunton, MA), and $3 \mathrm{ng}$ genomic DNA. If a primer pair failed three times to amplify template DNA that amplified with other primers, then it was scored as a null genotype. Fragment analysis followed separation on a genetic analyzer (CEQ 8000; Beckman Coulter, Fullerton, CA). Allele sizing and visualization were performed using the fragment analysis module of the CEQ 8000 software. Alleles were scored by fitting the peaks into bins less than 1 nucleotide.
Data Analyses. PowerMarker Version 3.25 (Liu and Muse, 2004) was used to calculate allele frequencies, deviations from Hardy-Weinberg equilibrium (HWE), observed $\left(\mathrm{H}_{\mathrm{o}}\right)$ and expected heterozygosities $\left(\mathrm{H}_{\mathrm{e}}\right)$, and polymorphism information content (PIC) of the $10 \mathrm{SSR}$ primer pairs that amplified up to two products in 44 of the 48 red raspberry genotypes (Table 3 ). Inbreeding coefficient $(F)$ was calculated in an Excel spreadsheet (Microsoft, Redmond, WA) as $\left[\mathrm{F}=1-\left(\mathrm{H}_{\mathrm{o}} / \mathrm{H}_{\mathrm{e}}\right)\right]$. For neighbor joining (NJ) cluster analysis of the 96 genotypes, individuals were scored for the presence or absence of each allele and each allele was treated as a separate locus. Genetic distance matrices were computed using PowerMarker with the proportion of shared alleles distance, $D_{s a}$ (Chakraborty and Jin, 1993):

$$
D_{s a}=\frac{1}{m} \sum_{j=1}^{m} \sum_{i=1}^{a j} \min \left(p_{i j}, q_{i j}\right)
$$

where $p_{i j}$ and $q_{i j}$ are the frequencies of the ith allele at the $j$ th locus, $\mathrm{m}$ is the number of loci examined, and $a_{j}$ is the number of alleles at the jth locus. MEGA Version 3.1 (Kumar et al., 2004) was used to create the dendrograms.

LinKage MAPPING. For mapping in the 'Glen Moy' $x$ 'Latham' $(\mathrm{GM} \times \mathrm{L})$ population, primers were initially tested on the parents and 10 selected progeny. For polymorphic loci, one primer was fluorescently end-labeled with FAM or HEX

Table 1. List of 13 simple sequence repeat (SSR) primer pairs evaluated in 48 raspberry and 48 blackberry genotypes. ${ }^{z}$

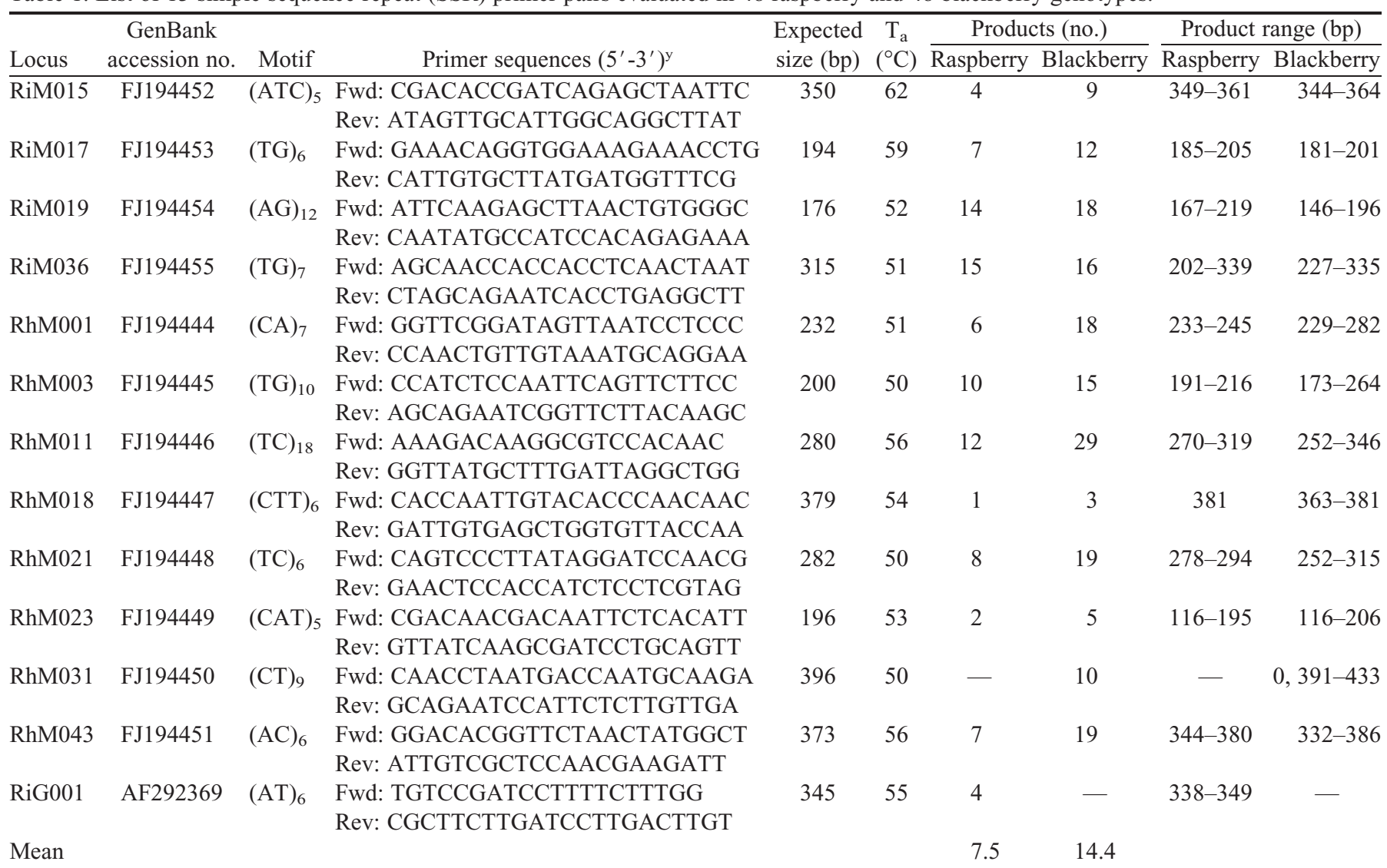

${ }^{\mathrm{z}}$ GenBank accessions numbers, SSR motif, forward and reverse primer sequences, expected product size, optimum annealing temperature $\left(\mathrm{T}_{\mathrm{a}}\right)$, and the number of polymerase chain reaction products and size ranges obtained in the 48 accessions of each crop type are included.

${ }^{\mathrm{y}} \mathrm{Fwd}=$ forward Rev $=$ reverse. 
Table 2. List of 48 raspberry and 48 blackberry genotypes evaluated with the 13 simple sequence repeats (SSRs) developed in this study. ${ }^{\mathrm{z}}$

\begin{tabular}{|c|c|c|c|}
\hline Cultivar name & PI no. & Pedigree & Ploidy \\
\hline \multicolumn{4}{|l|}{ Raspberry } \\
\hline Amity & PI 553487 & OSC $1839 \times$ OSC 1835 & $2 x$ \\
\hline Autumn Bliss & PI 553325 & Complex of $R$. idaeus, $R$. strigosus, $R$. arcticus, and $R$. occidentalis & $2 x$ \\
\hline Caroline & PI 653101 & 'GEO-1' × 'Heritage' & $2 x$ \\
\hline Centennial & PI 618456 & 'Meeker' $\times$ 'Skeena' & $2 x$ \\
\hline Chilcotin & PI 553537 & 'Sumner' $\times$ 'Newburgh' & $2 x$ \\
\hline Chilliwack & PI 553503 & BC 64-10-198 × 'Skeena' & $2 x$ \\
\hline Coho & PI 618392 & 'Lewis' × ORUS 520-48 & $2 x$ \\
\hline Comox & PI 553504 & BC 64-9-81 × 'Skeena' & $2 x$ \\
\hline Cuthbert & PI 553363 & Chance seedling of $R$. idaeus var. strigosus & $2 x$ \\
\hline Dormanred & PI 553425 & R. parvifolius $\times$ 'Dorsett' & $2 x$ \\
\hline Josephine & PI 653108 & 'Amity’ × 'Glenn Garry' & $2 x$ \\
\hline Killarney & PI 553479 & 'Chief' $\times$ 'Indian Summer' & $2 x$ \\
\hline Kitsilano & PI 618311 & 'Comox' × EM 3909/4 & $2 x$ \\
\hline Latham & PI 553564 & 'King' × 'Loudon' & $2 x$ \\
\hline Lloyd George ${ }^{y}$ & PI 643942 & Selection from wild red raspberry in Dorset, England & $2 x$ \\
\hline Malahat & PI 638206 & 'Meeker' × BC/SCRI7853/116 & $2 x$ \\
\hline Malling Enterprise & PI 553515 & 'Preussen' $\times($ 'Pyne's Royal' selfed $\times$ 'Lloyd George' selfed $)$ & $2 x$ \\
\hline Mandarin & PI 553493 & (R. parvifolius $\times$ 'Taylor') $\times$ 'Newburgh' & $2 x$ \\
\hline Meeker ${ }^{\mathrm{y}}$ & PI 553384 & 'Willamette' $\times$ 'Cuthbert' & $2 x$ \\
\hline Newburgh & PI 553369 & 'Newman' $\times$ 'Herbert' & $2 x$ \\
\hline Newman & PI 553448 & Chance seedling from a mix of several cultivars & $2 x$ \\
\hline Summit & PI 553502 & OSC $1838 \times$ OSC 1842 & $2 x$ \\
\hline Sumner & PI 553451 & 'Washington' $\times$ 'Tahoma' & $2 x$ \\
\hline Tahoma $^{y}$ & PI 553470 & 'Latham' $\times$ 'Lloyd George' & $2 x$ \\
\hline Trailblazer & PI 554015 & 'Augustred' $\times$ 'Cheyenne 63-16' & $2 x$ \\
\hline Tulameen & PI 618441 & 'Nootka' × 'Glen Prosen' & $2 x$ \\
\hline Veten & PI 553471 & 'Asker' × 'Lloyd George’ & $2 x$ \\
\hline Viking & PI 553368 & 'Cuthbert' $\times$ 'Marlboro' & $2 x$ \\
\hline Washington & PI 553380 & 'Cuthber't × 'Lloyd George' & $2 x$ \\
\hline Wawi & PI 553640 & 'Washington' × 'Willamette' & $2 x$ \\
\hline Willamette $^{\mathrm{y}}$ & PI 553362 & 'Newburgh' × ‘Lloyd George’ & $2 x$ \\
\hline WYO US 68-21 & PI 553520 & Presumed selection of $R$. strigosus & $2 x$ \\
\hline Zeva Herbsternte ${ }^{y}$ & PI 553428 & ('Indian Summer' $\times$ 'Romy') $\times$ 'Romy' & $2 x$ \\
\hline Zzopska Alena & PI 553473 & Selection from Kostinbrod, Bulgaria & $2 x$ \\
\hline \multicolumn{4}{|l|}{ Blackberry } \\
\hline Anderson & PI 553300 & Unknown eastern U.S. erect type & $4 x$ \\
\hline Ashton Cross & PI 553278 & Selection of wild European blackberry & $4 x$ \\
\hline Aurora & PI 553260 & OSC $616 \times$ OSC 73 & $8 x+2$ \\
\hline Austin Thornless ${ }^{\mathrm{y}}$ & PI 553292 & 'Mayes' open-pollinated seedling selection & $8 x$ \\
\hline Bailey $^{y}$ & PI 553243 & R. allegheniensis hybrid & $4 x$ \\
\hline Bedford Giant & PI 553277 & Self of veitchberry & $6 x$ \\
\hline Benenden & PI 553318 & $R$. trilobus $\times R$. deliciosus & $2 x$ \\
\hline
\end{tabular}


Table 2. Continued.

\begin{tabular}{|c|c|c|c|}
\hline Cultivar name & PI no. & Pedigree & Ploidy \\
\hline Black Diamond & PI 638257 & 'Kotata' × NZ 8610L-163 & $4 x$ \\
\hline Black Pearl & PI 638260 & ORUS $1117-11 \times$ ORUS $1122-1$ & $9 x$ \\
\hline Black Satin & PI 553272 & SIUS $47 \times$ 'Thornfree' & $4 x$ \\
\hline Boysen & PI 553336 & Presumed $R$. ursinus $\times R$. idaeus & $7 x$ \\
\hline Boysen 43 & PI 553341 & Clonal selection of 'Boysen' & $7 x$ \\
\hline Brazos & PI 553244 & $\mathrm{~F}_{2}$ of ('Lawton' $\times$ 'Nessberry') & $4 x$ \\
\hline Cascade & PI 553246 & 'Zielinski’ $\times$ 'Logan’ & $9 x$ \\
\hline Chehalem & PI 553273 & 'Santiam' $\times$ 'Himalaya' & $6 x$ \\
\hline Cherokee $^{y}$ & PI 553247 & 'Darrow' x 'Brazos' & $4 x$ \\
\hline Chester Thornless $^{\mathrm{y}}$ & PI 553322 & SIUS $47 \times$ 'Thornfree' & $4 x$ \\
\hline Darrow & PI 553250 & NY $15826 \times$ 'Hedrick' & $4 x$ \\
\hline Dirksen Thornless & PI 553251 & SIUS $47 \times$ 'Thornfree' & $4 x$ \\
\hline Illini Hardy & PI 553348 & NY $95 \times$ 'Chester Thornless' & $4 x$ \\
\hline Kiowa $^{\mathrm{y}}$ & PI 638183 & Ark. $791 \times$ Ark. 1058 & $4 x$ \\
\hline Kotata $^{\mathrm{y}}$ & PI 553293 & OSC $743 \times$ OSC 877 & $7 x$ \\
\hline Lincoln Logan & PI 553314 & Histogenic manipulation of thornless loganberry & $6 x$ \\
\hline Loch Ness & PI 638182 & Complex hybrid derived from 'Comanche', 'Chehalem' & $4 x$ \\
\hline Logan Thornless & PI 553258 & Thornless mutation of 'Logan' & $6 x$ \\
\hline Lucretia & PI 553253 & Selection of southern dewberry ( $R$. trivialis) & $7 x$ \\
\hline Marion $^{\mathrm{y}}$ & PI 553254 & 'Chehalem' $\times$ 'Olallie' & $6 x$ \\
\hline Merton Thornless & PI 553276 & 'John Innes' selfed & $4 x$ \\
\hline Metolius & PI 638262 & 'Douglass' $\times$ 'Kotata' & $6 x$ \\
\hline Navaho $^{\mathrm{y}}$ & PI 553343 & Ark. $583 \times$ Ark. 631 & $4 x$ \\
\hline Nightfall & PI 638263 & 'Marion' $\times$ 'Waldo' & $6 x$ \\
\hline Tayberry $^{y}$ & PI 553351 & 'Aurora' × SHRI 626/67 & $4 x$ \\
\hline Tillamook & PI 553354 & Selected from the wild in Oregon & $10 x$ \\
\hline Waldo & PI 553334 & OSC $1122 \times$ OSC 1367 & $6 x$ \\
\hline Watlab $^{y}$ & PI 271519 & Selection made in Washington State from seed collected wild in India & $2 x$ \\
\hline
\end{tabular}

 ${ }^{\mathrm{y}}$ Genotypes used to initially screen SSR primer pairs for amplification and polymorphism. Additional red raspberry cultivars included Malling Joy, Krupna Dvorodna, Pathfinder, and Rose de Cote d'Or.

and used to genotype 188 individuals of (Graham et al., 2004) using a 3730 DNA Analyzer with ROX350 (Applied Biosystems, Carlsbad, CA) used as an internal size standard. Allele sizes were determined using GENEMAPPER (Applied Biosystems). JoinMap Version 2.0 (Stam and Vanooijen, 1995) was used to construct the linkage map for population type CP (cross-pollinated). Linkage groups were separated at logarithm of odds (LOD) scores between 7.0 and 10.0 and map distances were calculated using the Kosambi mapping function as described previously (Graham et al., 2004, 2006, 2009).

In the 'Autumn Bliss' $\times$ 'Malling Jewel' $(\mathrm{AB} \times \mathrm{MJ})$ population, PCRs were performed on genomic DNA of the parents following the methods of Fukatsu et al. (2005) with the minor modifications of Sargent et al. (2009). Reactions were then carried out following the touchdown protocol of
Fernández-Fernández et al. (2008) between 55 and $50{ }^{\circ} \mathrm{C}$. Products were sized by electrophoresis using an ABI 3100 Genetic Analyzer with an internal size standard (500 LIZ ${ }^{\mathrm{TM}}$ ) using GENESCAN ${ }^{\circledR} 3.7$ and GENOTYPER ${ }^{\circledR} 3.7$ software (Applied Biosystems). Primer pairs amplifying a common single allele in both parents were tested on a subset of eight seedlings for evidence of polymorphism. All primers revealing polymorphisms were subsequently used to score 94 individuals of the $\mathrm{AB} \times \mathrm{MJ}$ progeny. These data were analyzed jointly with unpublished SSR and random amplified polymorphism DNA data for this progeny to determine map positions. Chi square tests of goodness-of-fit to single locus Mendelian segregation were carried out, and cosegregations were analyzed for evidence of linkage using JoinMap Version 4.0 (Van Ooijen, 2006). Linkage groups were separated at LOD scores between 
Table 3. Diversity estimates and map locations for 10 simple sequence repeats using 44 red raspberry cultivars that amplified up to two products per primer pair. ${ }^{z}$

\begin{tabular}{lccccccc}
\hline & & & & & HWE & \multicolumn{2}{c}{ Linkage group } \\
\cline { 7 - 9 } Locus & $\mathrm{H}_{\mathrm{o}}$ & $\mathrm{H}_{\mathrm{e}}$ & $\mathrm{PIC}$ & $\mathrm{F}$ & $(P$ value $)$ & $\mathrm{GM} \times \mathrm{L}$ & $\mathrm{AB} \times \mathrm{MJ}$ \\
\hline RiM015 & 0.60 & 0.66 & 0.52 & 0.09 & 0.72 & 3 & Unlinked \\
RiM017 & 0.53 & 0.41 & 0.47 & -0.29 & 0.06 & 7 & 7 \\
RiM019 & 0.84 & 0.89 & 0.82 & 0.06 & 0.34 & 5 & 5 \\
RiM036 $^{\mathrm{y}}-$ & - & - & - & - & - & - & 6 \\
RhM001 & 0.33 & 0.29 & 0.29 & -0.14 & $0.02^{*}$ & 2 & 2 \\
RhM003 & 0.84 & 0.93 & 0.81 & 0.10 & 0.63 & 2 & 2 \\
RhM011 & 0.80 & 0.84 & 0.78 & 0.05 & 0.37 & 7 & 7 \\
RhM021 & 0.45 & 0.39 & 0.43 & -0.15 & $0.003^{*}$ & 5 & $\mathrm{NS}^{\mathrm{x}}$ \\
RhM023 & 0.50 & 0.98 & 0.37 & 0.49 & $0 *$ & - & $\mathrm{NS}^{*}$ \\
RhM043 & 0.55 & 0.43 & 0.52 & -0.28 & $0.008^{*}$ & - & $4^{\mathrm{w}}$ \\
RiG001 & 0.53 & 0.20 & 0.46 & -1.65 & $0 *$ & - & $\mathrm{NS}$ \\
Mean & 0.60 & 0.61 & 0.55 & & & &
\end{tabular}

${ }^{\mathrm{z}}$ Observed $\left(\mathrm{H}_{\mathrm{o}}\right)$ and expected heterozygosities $\left(\mathrm{H}_{\mathrm{e}}\right)$, polymorphism information content (PIC), inbreeding coefficient $(\mathrm{F})$, deviations from Hardy-Weinberg equilibrium (HWE), and linkage group assignments in the 'Glen Moy' $\times$ 'Latham' $(\mathrm{GM} \times \mathrm{L})$ and 'Autumn Bliss' $\times$ 'Malling Jewel' $(\mathrm{AB} \times \mathrm{MJ})$ populations.

${ }^{y}$ Excluded from diversity analysis as a result of amplification of multiple loci in some genotypes; however, only one locus amplified in the $\mathrm{AB} \times \mathrm{MJ}$ progeny.

${ }^{x}$ No segregation observed in this progeny.

${ }^{\text {w} M a i n ~ l o c u s ~ s h o w s ~ n o ~ s e g r e g a t i o n ~ i n ~ t h e ~} \mathrm{AB} \times \mathrm{MJ}$; however, a secondary locus (279 bp) segregated and could be mapped.

*Significant deviation from $\operatorname{HWE}(P<0.05)$.

2 and 10. Genetic distances were calculated using the Kosambi mapping function.

\section{Results and Discussion}

Polymorphism AND ESTIMATION OF GENETIC Diversity. Eleven of the 13 SSR primer pairs amplified and were polymorphic in raspberry but RhM031 did not amplify a product and RhM018 was monomorphic. In blackberry, 12 of the 13 SSR primer pairs amplified a product but RiG001 from red raspberry did not. As expected, the number of products per primer pair at the 12 SSRs that successfully amplified was higher in blackberry than in raspberry (Table 1). The range was one to 15 alleles in the 48 red raspberries (average, 7.5) and three to 29 in the 48 blackberries (average, 14.4) (Table 1).

RhM31 generated nine products in blackberry but failed to amplify 'Benenden', 'Ebano', 'Tayberry', and 'Watlab' and all red raspberry accessions (Table 1). In four red raspberry accessions, more than two amplicons were observed with one to three of the SSR primer pairs and were excluded from diversity calculations. These accessions included: 'Trailblazer' at RhM001, RhM011, and RhM021; 'Amity' at RhM003; 'Zeva Herbsternte' at RiM19 and RhM001; and 'Dormanred' at RiM017. Diversity estimates were calculated for 10 of the 12 SSRs that amplified in red raspberry (Table 3). RiM036 was difficult to score and amplified more than two DNA fragments in diploid accessions of red raspberry, indicating its possible multilocus nature and thus it was not included in diversity analysis. RhM018 amplified in each of the accessions tested but was monomorphic (381 bp) in red raspberry. It generated two unique products in blackberry (363 bp in 'Flordagrand', 366 bp in 'Eldorado') in addition to the 381-bp most-frequent PCR product $(96 \%) . \mathrm{H}_{\mathrm{o}}$ and $\mathrm{H}_{\mathrm{e}}$ and PIC of the remaining 10 SSRs were $0.60,0.61$, and 0.55 , on average, respectively (Table 3 ). Five (RiM015, RiM019, RhM003, RhM011, RhM043) of the 10 SSRs evaluated can be considered highly polymorphic [PIC greater than 0.5 according to Botstein et al. (1980)]. These sequences were dinucleotide repeats, which have been reported to be more polymorphic than trinucleotide repeats. In fact, the lowest PIC (0.52) was for the trinucleotide-containing RiM015. Five SSRs (RhM001, RhM021, RhM023, RhM043, RiG001) were not in HWE $(P \leq 0.05$; Table 3$)$, an indication of the presence of null alleles. $F$ ranged from -1.65 to 0.49 with a mean of 0.17 . A high $F$ value, which allows the identification of putative null alleles, was observed at RhM023. The presence of null alleles in genomic SSRs, thought to be the result of polymorphisms in the primer binding sites, is well documented. Population subdivision among the 44 samples could also be a reason for these results. The best SSR loci, based on high $\mathrm{H}_{\mathrm{o}}$, $\mathrm{H}_{\mathrm{e}}$, and PIC and low $F$, were RiM019, RhM003, and RhM011. Furthermore, these three loci were easy to score and were sufficient to identify each of the raspberry and blackberry genotypes as unique.

MAPPING. Five SSR markers (RiM017, RiM019, RhM001, RhM003, RhM011) showed segregation in both mapping populations and were assigned to the same linkage groups in both (Table 3 ) indicating good colinearity between $\mathrm{AB} \times \mathrm{MJ}$ currently being developed (Fernández-Fernández, unpublished data) and the more saturated GM $\times$ L map (Graham et al., 2004, 2006, 2009; Woodhead et al., 2008). RiM015 segregated in both progenies and was mapped in $\mathrm{GM} \times \mathrm{L}$ but remained unlinked in the less saturated $\mathrm{AB} \times \mathrm{MJ}$ progeny (Table 3 ). RhM021 only showed segregation in the GM $\times$ L and was mapped to LG5. Conversely, RiM036 amplified multiple loci in several accessions and could not be mapped in GM $\times \mathrm{L}$ but amplified a single segregating locus in $\mathrm{AB} \times \mathrm{MJ}$ and was assigned to LG6 (Woodhead et al., 2008). Two markers (RhM023, RhM043) showed no segregation in either cross. Finally, the RhM043 main locus showed no segregation in either progeny; however, a weaker secondary locus could be reliably amplified in $\mathrm{AB} \times \mathrm{MJ}$ and was mapped to LG4 (Woodhead et al., 2008).

Allele frequency in Raspberry and blackberry. At RhM23, 97\% of the red raspberry accessions displayed a single genotype (116 of 195) whose alleles were also most frequent in blackberry. At RhM043, the 376-bp allele was most frequent in both crops. In the remaining eight primer pairs (RiM019, RiM015, RiM017, RhM001, RhM003, RhM011, RhM021, RhM043), the most frequent allele in red raspberry was different from in blackberry.

NEIGHBOR JOINING CLUSTER ANALYSIS. Microsatellite markerbased NJ cluster analysis is used to illustrate genotype relationships. Despite the small number of SSRs used in this study for accurate determination of genotype relationships, NJ clustering separated accessions according to crop type and mostly based on ancestry and breeding program and is discussed further. Rubus cultivars were separated from each other except for clonal variants ('Logan Thornless' and 'Lincoln Logan', 'Boysen' and 'Boysen 43') and two pairs of cultivars ('Tillamook' and 'Cascade', 'Comox and 'Chilliwack'). Inability to distinguish clonal variants by SSR analysis agrees with previous reports in other clonally propagated plants such as pear [Pyrus (Yamamoto et al., 2001)] and apple [Malus (Hokanson et al., 1998)]. The inability to differentiate between 'Tillamook' and 'Cascade' may not be surprising (C. Finn, personal 
communication). 'Cascade' was released in 1940 by the USDA-ARS blackberry breeding program in Corvallis. This old trailing blackberry cultivar could have escaped into the wild and then later been identified as a superior, hermaphroditic selection of the native $R$. ursinus. It was named 'Tillamook' after the coastal Oregon community where it was found. 'Comox' and 'Chilliwack' were adjacent on the screenhouse bench and could have been misidentified. New sources of trueto-name 'Comox' and 'Chilliwack' have been requested. A heterogeneous group of cultivars containing uncommon species in their background did not cluster in either crop type (Figs. 1 and 2). This heterogeneous group contained raspberry ('Dormanred', 'Trailblazer', and 'Zeva Herbsternte'), blackberry ('Flordagrand', 'Benenden', and 'Bedford Giant'), and the "hybridberry" (blackberry $\times$ raspberry) 'Sunberry'. In each of

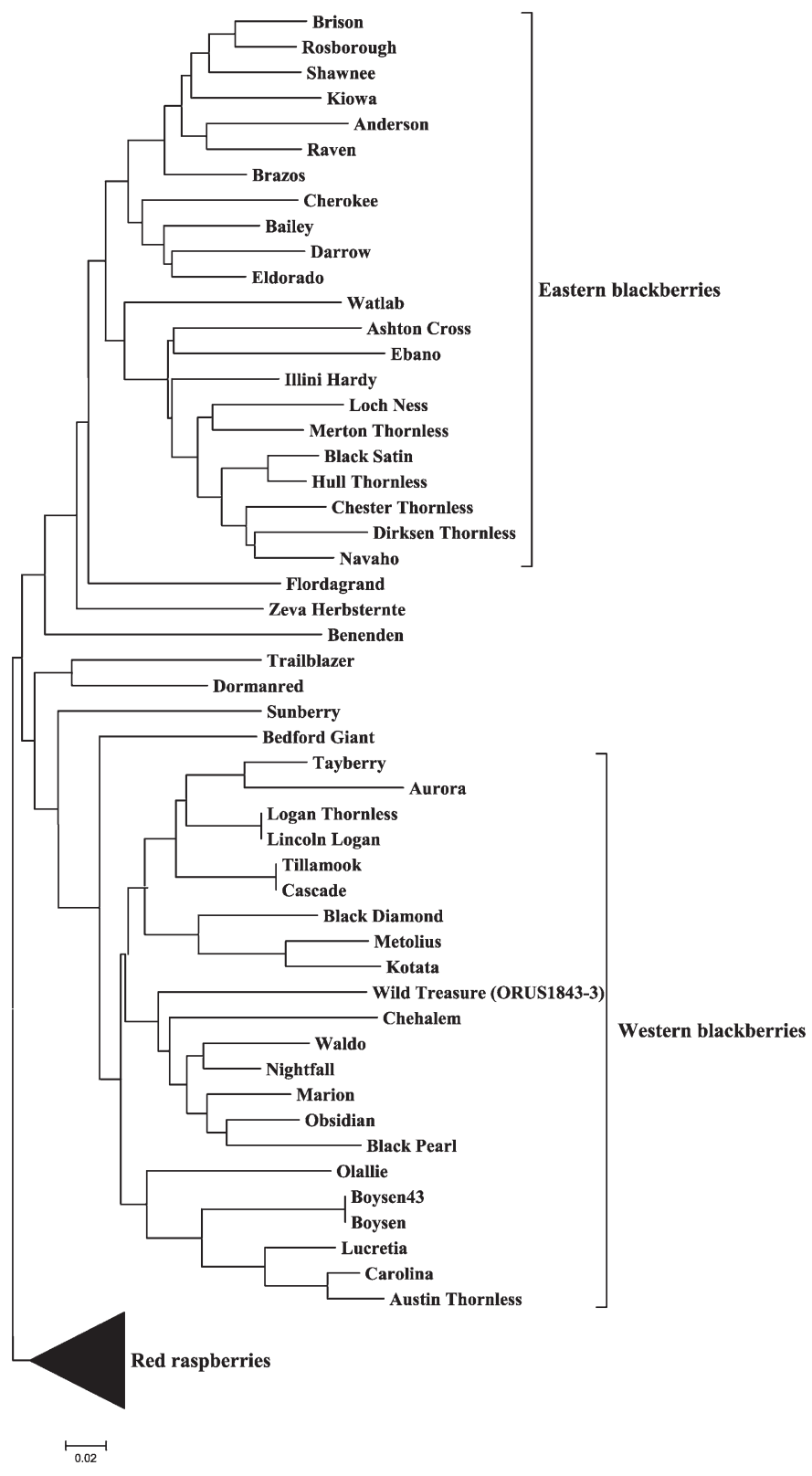

Fig. 1. Neighbor joining cluster analysis of 48 blackberries based on 12 microsatellite primer pairs (groups containing red raspberry were collapsed).

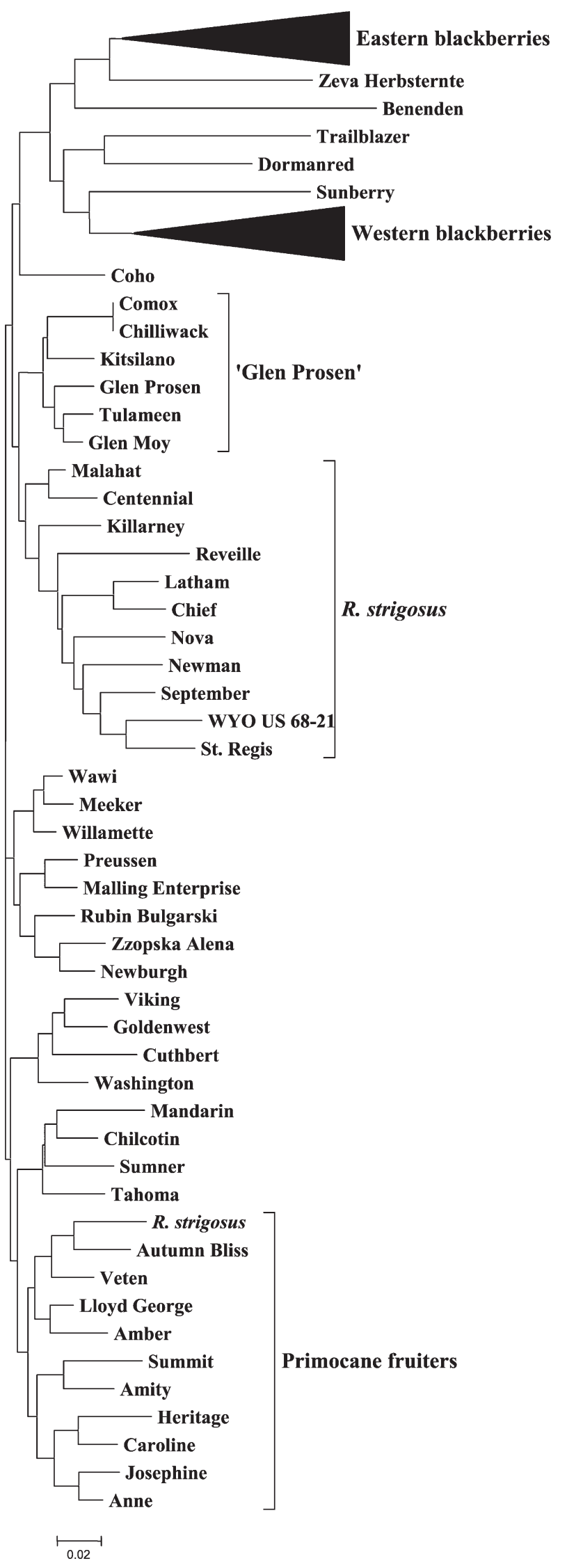

Fig. 2. Neighbor joining cluster analysis of 48 red raspberries based on 12 microsatellite (groups containing blackberries were collapsed). 
these accessions, we observed a minimum of two unique alleles ('Flordagrand'). The largest number of unique alleles was obtained in 'Benenden' (eight) and in 'Zeva Herbsternte' (six).

Blackberry genotypes are subdivided into two primary clades: the "eastern" tetraploid cultivars and "western" cultivars with higher ploidy levels. The eastern North American blackberry can further be classified by cane architecture (semierect or erect) (Clark, 2005) and by thornlessness. In the NJ dendrogram, they were separated accordingly into two groups: erect thorny and semitrailing thornless. Cultivars in the erect subgroup have mostly $R$. allegheniensis as a founder (Stafne et al., 2003). According to Stafne and Clark (2004), $R$. allegheniensis had the highest mean genetic contribution $(18.93 \%)$ indicating that it comprised a large portion of the total genetic makeup in the 13 blackberry cultivars in the study. $R$. frondosus and $R$. argutus were next with contributions of $17 \%$ and $12 \%$, respectively. The genetic contribution of these founding clones to the cultivars is through the intermediate parents 'Brazos' and 'Darrow', which were used extensively as parents in breeding programs because they produced exceptional offspring (Stafne et al., 2005). 'Anderson', an erect cane type, has an unknown pedigree but grouped with the eastern blackberries possibly as a result of that trait.

The second eastern North American blackberry cluster contained thornless cultivars that are either semierect or trailing. Thornlessness is a desirable trait in blackberry. $R$. ulmifolius var. inermis is used to transmit the recessive thornless gene to modern blackberry cultivars through the intermediate parents 'John Innes' and 'Thornfree' (Stafne et al., 2003). 'Ashton Cross', a thorny, wild selection from Europe, was placed in this group. This cultivar was successful in northern Britain because it flowers late. Scottish breeders combined the rapid fruit maturation of 'Ashton Cross', spinelessness of 'Thornfree', and erectness and early flowering of 'Darrow', resulting in 'Loch Ness' after several generations of breeding (Jennings, 1988).

The second clade of blackberry accessions is composed of the trailing high ploidy (Table 2) blackberry or dewberry of North America. Rubus ursinus was widely used in breeding western blackberry, whereas $R$. laciniatus [e.g., 'Oregon Evergreen' and $R$. armeniacus plants (synonym = 'Himalaya', 'Himalaya Giant')] were also imported from Europe as potential crops for the region. Rubus ursinus made a genetic contribution through the intermediates 'Aughinbaugh', 'Santiam', and 'Zielinski'. A thornless selection of 'Austin Mayes', a hybrid of $R$. baileyanus $\times R$. argutus, was released as 'Austin Thornless' in 1924. This clone has been used extensively for breeding almost-thornless seedlings (Finn et al., 2005).

Raspberry accessions grouped mostly along expected lines based on pedigree. Most raspberry cultivars are derived from the european raspberry, $R$. idaeus, and a few from the american raspberry, $R$. strigosus. A three-step plan was used in raspberry breeding: 1) many cultivars were selected within $R$. idaeus and $R$. strigosus either from chance discoveries or from families of open-pollinated seedlings; 2) some selections were used to produce $R$. idaeus $\times R$. strigosus hybrids; and 3) hybrid cultivars and some of the earlier chance discoveries were crossed to produce modern cultivars (Jennings, 1988). The grouping of raspberries based on the contribution of $R$. idaeus, $R$. strigosus, and crosses of $R$. idaeus and $R$. strigosus in their genetic makeup was suggested in the dendrogram. In the NJ dendrogram, the 'Glen Prosen' subcluster consisted of cultivars that had 'Glen Prosen' or 'Comox' as immediate parents. The $R$. strigosus group contained cultivars derived from this species through 'Newman' or 'Ranere' (synonym = 'St. Regis'). The next three subclusters consist of cultivars from the $R$. idaeus background separated into subgroups based on the founding clones 'Lloyd George', 'Hudson River Antwerp', and 'Creston'. In a study by Dale et al. (1993), four founding clones occurred in more than 90 raspberry pedigrees: 'Lloyd George', 'Hudson River Antwerp', 'English Globe', and 'Highland Hardy'. The latter three are found in the intermediate parents 'Cuthbert' and 'Marlboro'. The raspberry breeding strategy used resulted in the development of cultivars based on few parents. 'Lloyd George', 'Preussen', and 'Newburgh' are in the pedigrees of a number of cultivars in this group. The final cluster consisted of primocane fruiting (fall fruiting) cultivars that were developed from a relatively small genetic pool.

\section{Conclusion}

Of 13 SSRs evaluated in 48 genotypes of raspberries and 48 accessions of blackberries, three loci (RiM019, RhM003, RhM011) were highly polymorphic in each crop type, easy to score, and were mapped to single loci. These three SSRs should be evaluated across laboratories and platforms for their potential as a universal red raspberry and blackberry fingerprinting set. SSR-based analysis cannot be used to infer phylogenetic relationships. However, despite the small number of SSRs used, we observed that NJ clustering grouped each of the crop types together, mostly based on pedigrees and the originating breeding program. Blackberries were also divided into the eastern types of lower ploidy and the western cultivars of higher ploidy.

\section{Literature Cited}

Amsellem, L., C. Dutech, and N. Billotte. 2001. Isolation and characterization of polymorphic microsatellite loci in Rubus alceifolius Poir. (Rosaceae), an invasive weed in La Réunion island. Mol. Ecol. Notes 1:33-35.

Bassil, N.V., B. Gilmore, J.M. Oliphant, K. Hummer, and J.A. Henning. 2008. Genic SSRs for European and North American hop (Humulus lupulus L.). Genet. Resources Crop Evol. 55:955-969.

Botstein, D., R.L. White, M. Skolnick, and R.W. Davis. 1980. Construction of genetic linkage map in man using restriction fragment length polymorphisms. Amer. J. Hum. Genet. 32:314-331. Chakraborty, R. and L. Jin. 1993. Determination of relatedness between individuals using DNA fingerprinting. Hum. Biol. 65: 875-895.

Clark, J.R. 2005. Changing times for eastern United States blackberries. HortTechnology 15:491-494.

Dale, A., P.P. Moore, R.J. McNicol, T.M. Sjulin, and L.A. Burmistrov. 1993. Genetic diversity of red raspberry varieties throughout the world. J. Amer. Soc. Hort. Sci. 118:119-129.

Fernández-Fernández, F., K. Evans, J. Clarke, C. Govan, C. James, S. Marič, and K. Tobutt. 2008. Development of an STS map of an interspecific progeny of Malus. Tree Genet. Genomes 4:469-479.

Finn, C.E., B.B. Yorgey, B.C. Strik, R.R. Martin, and C. Kempler. 2005. 'Obsidian' trailing blackberry. HortScience 40:2185-2188.

Fukatsu, E., K. Isoda, T. Hirao, M. Takahashi, and A. Watanabe. 2005. Development and characterization of simple sequence repeat DNA markers for Zelkova serrata. Mol. Ecol. Notes 5:378-380.

Glenn, T.C. and N.A. Schable. 2005. Isolating microsatellite DNA loci. Methods Enzymol. 395:202-222.

Graham, J., K. Smith, K. MacKenzie, L. Jorgenson, C. Hackett, and W. Powell. 2004. The construction of a genetic linkage map of red raspberry (Rubus idaeus subsp. idaeus) based on AFLPs, genomicSSR and EST-SSR markers. Theor. Appl. Genet. 109:740-749. 
Graham, J., K. Smith, I. Tierney, K. MacKenzie, and C.A. Hackett. 2006. Mapping gene $\mathrm{H}$ controlling cane pubescence in raspberry and its association with resistance to cane botrytis and spur blight, rust and cane spot. Theor. Appl. Genet. 112:818-831.

Graham, J., K. Smith, M. Woodhead, and J. Russell. 2002. Development and use of simple sequence repeat SSR markers in Rubus species. Mol. Ecol. Notes 2:250-252.

Graham, J., K. Smith, M. Woodhead, and J. Russell. 2009. Mapping QTLs for developmental traits in raspberry from bud break to ripe fruit. Theor. Appl. Genet. 118:1143-1155.

Hokanson, S.C., A.K. Szewc-McFadden, W.F. Lamboy, and J.R. McFerson. 1998. Microsatellite (SSR) markers reveal genetic identities, genetic diversity and relationships in a Malus $\times$ domestica Borkh. core subset collection. Theor. Appl. Genet. 97:671-683.

Huang, X. and A. Madan. 1999. Cap3: A DNA sequence assembly program. Genome Res. 9:868-877.

Jennings, D.L. 1988. Raspberries and blackberries: Their breeding, diseases and growth. Academic Press, London, UK.

Kumar, S., K. Tamura, and M. Nei. 2004. MEGA3: Integrated software for molecular evolutionary genetics analysis and sequence alignment. Brief. Bioinform. 5:150-163.

Lewers, K., C. Saski, B. Cuthbertson, D. Henry, M. Staton, D. Main, A. Dhanaraj, L. Rowland, and J. Tomkins. 2008. A blackberry (Rubus L.) expressed sequence tag library for the development of simple sequence repeat markers. BMC Plant Biol. 8:69.

Liu, K. and S. Muse. 2004. Powermarker: New genetic data analysis software. Version 3.25. 10 Oct. 2005. <http://www.powermarker.net>. Lopes, M.S., G.B. Maciel, D. Mendonca, F.S. Gil, and A. Da Camara Machado. 2006. Isolation and characterization of simple sequence repeat loci in Rubus hochstetterorum and their use in other species from the Rosaceae family. Mol. Ecol. Notes 6:750-752.

Rozen, S. and H.J. Skaletsky. 2000. Primer 3 on the WWW for general users and for biologist programmers, p. 365-386. In: S.A. Krawetz and S. Misener (eds.). Bioinformatics methods and protocols: Methods in molecular biology. Humana Press, Totowa, NJ.
Sargent, D.J., A. Marchese, D.W. Simpson, W. Howard, F. FernándezFernández, A. Monfort, P. Arús, K.M. Evans, and K.R. Tobutt. 2009. Development of 'universal' gene-specific markers from Malus pumila cDNA sequences, their mapping and use in synteny studies within Rosaceae. Tree Genet. Genomes 5:133-145.

Stafne, E.T. and J.R. Clark. 2004. Genetic similarity among eastern North American blackberry cultivars based on pedigree analysis. Euphytica 139:95-104.

Stafne, E.T., J.R. Clark, M.C. Pelto, and J.T. Lindstrom. 2003. Discrimination of Rubus cultivars using RAPD markers and pedigree analysis. Acta Hort. 626:119-124.

Stafne, E.T., J.R. Clark, C.A. Weber, J. Graham, and K.S. Lewers. 2005. Simple sequence repeat (SSR) markers for genetic mapping of raspberry and blackberry. J. Amer. Soc. Hort. Sci. 130:722-728.

Stam, P. and J.W. Vanooijen. 1995. JoinMap version 2.0: Software for the calculation of genetic linkage maps. Centrum voor Plantenveredelings-en Reproduktieonderzoek. Wageningen, The Netherlands.

Temnykh, S., G. De Clerck, A. Lukashova, L. Liponitch, S. Cartinhour, and S.R. McCouch. 2001. Computational and experimental analysis of microsatellites in rice (Oryza sativa L.): Genetic marker potential. Genome Res. 11:1441-1452.

U.S. Department of Agriculture. 2006. Oregon berries. Portland. 10 Apr. 2010. <http://www.oregon-berries.com/common/docs/berries_ stats_2006.pdf>.

Van Ooijen, J.W. 2006. JoinMap version 4.0, software for the calculation of genetic linkage maps in experimental populations. Kyazma, Wageningen, The Netherlands.

Woodhead, M., S. McCallum, K. Smith, L. Cardle, L. Mazzitelli, and J. Graham. 2008. Identification, characterisation and mapping of simple sequence repeat (SSR) markers from raspberry root and bud ESTs. Mol. Breed. 22:555-563.

Yamamoto, T., T. Kimura, Y. Sawamura, K. Kotobuki, Y. Ban, T. Hayashi, and N. Matsuta. 2001. SSRs isolated from apple can identify polymorphism and genetic diversity in pear. Theor. Appl. Genet. 102:865-870. 